\section{Questión}

Periodismo / Comunicación ISSN 1669-6581
- Av. $44 \mathrm{~N}^{\circ} 676,1^{\circ}$ piso

CP 1900 - La Plata - Argentina

(i) www.perio.unlp.edu.ar/question

Estamos en un momento muy fuerte de la disputa por la representación legítima de la pandemia

Rossana Reguillo - Carlos Milito

https://doi.org/10.24215/16696581e362

\title{
"Estamos en un momento muy fuerte de la disputa por la representación legitima de la pandemia"
}

\section{"We are at a very strong moment in the dispute over the legitim representation of the pandemic"}

Coordinadora General de @Signa Lab ITESO con la colaboración de todo el equipo del Laboratorio. Investigadora de Ciencias Sociales y activista mexicana. Es Doctora en Ciencias Sociales por la Universidad de Guadalajara y el Centro de Investigación y Estudios Superiores en Antropología Social.

\section{Entrevista}

Carlos Milito.

https://orcid.org/0000-0002-5874-6951 cmilito@perio.unlp.edu.ar Magister en Comunicación y gestión de procesos comunicacionales FPyCS UNLP Profesor Titular del Taller de producción de contenidos y narrativas sonoras y radiales Director de la Especialización en Comunicación radiofónica - FPyCS UNLP Coordinador de 1894radioonline de Villa Elisa, Provincia de Buenos Aires Locutor comercial de Relatores. Transmisiones Deportivas por la app y AM530 Somos Radio Integrante del IICom (Instituto de Investigaciones en Comunicación) FPCS UNLP

\section{Resumen}

Rossana Reguillo describe el estado de situación de México ante el virus. Sostiene que se está jugando en los medios de comunicación masiva y en las redes sociodigitales la legitimación de 
la interpretación de la pandemia y advierte que la emergencia demanda pensar una vez más la comunicación y la metodología.

\section{Palabras Claves}

Periodismo - medios de comunicación - redes sociodigitales - noticias - comunicar -

Pandemia - Noticias falsas - Disputa por la representatividad

\section{Summary}

Rossana Reguillo describes Mexico's state of state of situation with the virus. It argues that the legitimization of the interpretation of the pandemic is being played in the mass media and social networks and warns that the emergency requires a thought once again of communication and methodology.

\section{Keywords}

Journalism - media - socio-digital networks - news - communicate - Pandemic - Fake news Dispute over representativeness

\section{Enlace}

https://ar.ivoox.com/es/51718097 